\title{
Effects of freezing onfunctionality and physicochemical properties of a 3D-human skin model
}

\begin{abstract}
Background: Three-dimensional skin substitutes reconstructed by tissue engineering have strong potential to emulate skin conditions in vivo, although their production necessitates a relatively long period of time. Storage of cry preserved substitutes among time, using some kind of banking system, would be a conceivable solution to make their utilization more appealing for dermo pharmaceutical testing. This study evaluated the effects of freezing at $-20^{\circ} \mathrm{C}$ over a period of 2 months on the structural and physicochemical properties of skin substitutes produced by tissue engineering.
\end{abstract}

Method: Skin substitutes were produced according to the self-assembly method which is based on fibroblasts' capacity to create their own extracellular matrix in vitro. Characterization of frozen skin substitutes was performed by percutaneous absorption analyses and attenuated total reflectance Fournier transform infrared spectroscopy (ATR-FTIR) to compare functionality and physicochemical properties of a frozen/ thawed stratum corneum with a fresh counterpart.

Results: Permeability analyses revealed a significant increase in the penetration profiles of benzoic acid through frozen/thawed skin substitutes although ATR-FTIR results showed no significant differences on the lipid conformation of human skin and skin substitutes after the freezing process.

Conclusion: The functionality of the skin substitutes appeared affected by a freezing process nevertheless their structural integrity was preserved.

Keywords: cryopreservation, skin, tissue engineering, skin substitutes, spectroscopy, percutaneous absorption
Volume I Issue 2 - 2017

\author{
Roxane Pouliot \\ Departement of Dermatology, University Laval, Canada
}

Correspondence: Roxane Pouliot, Département of Dermatology, Ferdinand Vandry Pavillon, 1050 Avenue de la Médecine, Québec City, QC GIV 0A6, Canada, Tel I-4I8-6562131,Email roxane.pouliot@pha.ulaval.ca

Received: April 05, 2017 | Published: April 24, 2017
Abbreviations: NHS, human skin; FNHS, frozen human skin; SS, skin substitute; FSS, frozen skin substitute

\section{Short Abstract}

Three-dimensional skin substitutes reconstructed by tissue engineering have strong potential to emulate skin conditions in vivo, although their production necessitates a relatively long period of time. Storage of cry preserved substitutes among time, using some kind of banking system, would be a conceivable solution to make their utilization more appealing for dermopharmaceutical testing. This study evaluated the effects of freezing at $-20^{\circ} \mathrm{C}$ over a period of 2 months on the structural and physicochemical properties of skin substitutes produced by tissue engineering.

\section{Introduction}

Located at the interface between the human body and the exterior environment, skin is the first line of defense against pathogens, chemicals, and harmful mechanical stimuli. ${ }^{1}$ Due to its large surface area and its structural and functional complexity, regenerating a complete human skin represents a big challenge. Over the past years, different human skin substitute models have evolved in order to treat victims of severe burns and chronic cutaneous wounds. ${ }^{2}$ Skin substitutes are useful in both applied and fundamental fields of research. They can be grafted as skin replacement in clinical applications or used for various types of skin tests, such as dermopharmacology and toxicology studies. ${ }^{2,3}$ Skin substitutes properties must be as close as possible to those of normal skin. ${ }^{4}$

Over the past decade or so, the use of animals in fundamental and applied research has been subject to social debates, and this has led to the creation of more restrictive legislations, such as the addition of the Seventh Amendment to the European Union's Cosmetic Directive. ${ }^{4}$ Utilization of skin substitutes to perform tests allowed for the elimination, or at least reduction, of controversial animal testing. Moreover, as animal skin differs in many ways to human skin, well representative skin substitutes could improve the validity of performed tests. ${ }^{5}$ In order to increase efficiency, rapid access to skin substitutes is critical. Therefore, optimized storage methods are needed. ${ }^{6}$

Cryopreservation is an approach that has been under much investigation recently. The impact of various freezing conditions has been tested on animal and human skins. Among all tests performed, permeability analysis is one of the most commonly used in the literature. This test is based on the fact that skin, despite its crucial involvement as a barrier against exogenous material, remains permeable to most substances.

Various factors influence absorption level. ${ }^{7,8}$ Depending on their characteristics, molecules diffuse through skin by various pathways. They can use the transepidermic and the transannexiel pathways. ${ }^{9}$ The 
first one implies the diffusion of chemicals directly through the skin: they can diffuse in a Tran's cellular way between keratinocytes of the stratum corneum layer or in an intercellular way through intercellular spaces. The second one implies the diffusion of chemicals through hair follicles and sweat ducts.

The Stratum corneum is therefore the most important layer implied in the skin permeability. This layer is mainly constituted of corneocytes, which are mortalized final cornification phase keratinocytes. These cells are interlocked in a lipid intercellular matrix, mainly constituted of ceramides, cholesterol and free fatty acids. ${ }^{10}$ The specific organization of these lipids plays an important role in the barrier functionality of the stratum corneum ${ }^{11}$ which may be characterized by ATR-FTIR analysis. ${ }^{11,12}$

Permeability analyses have been performed on different animals' frozen skin, such as pig, ${ }^{13-15}$ rat ${ }^{16-18}$ mouse, ${ }^{19}$ cattle, ${ }^{20}$ monkey, ${ }^{21}$ and dog. ${ }^{22}$ In most of the cases, analyses showed an augmentation of the flux. One exception can be noted for Schreiber et al. who observed no differences in the flux of caffeine and testosterone through porcine skin. ${ }^{23}$ However, these analyses cannot be conclusive for human skin as it differs too greatly from animal skin. Consequently, other experiments have also been performed on frozen human skin using various penetration agents such as water. ${ }^{24,25}$ chromone acid, ${ }^{26}$ m-DEET, ${ }^{27}$ organic solvents, ${ }^{28,29}$ and T-2 toxin. ${ }^{21}$ While the ones using water or organic solvents showed no impact, the others showed flux variation: freezing increased penetration of chromone acid and T-2 toxin, but decreased permeability of m-DEET. Different methods were used for the frozen storage. While Burch et al. used Petri dishes with cotton soaked in a solution of sodium chloride, Astley et al. ${ }^{26}$ rolled their skin biopsies in sterile gauzes soaked in a salt solution (Hank's balanced salt) and stored them in capped containers..$^{30}$ Bronaugh et al. ${ }^{25}$ used sealed plastic bags, while Swar brick et al ${ }^{26}$ used aluminum foil.

Some of the developed skin substitutes have also been tested for cryopreservation. Different methods were used for epidermal substitute cryopreservation, such as the use of dimethyl sulfoxide ${ }^{6,31,32}$ and trehalose as cryoprotectants. ${ }^{6}$ Dimethyl sulfoxide has also been tested on dermal substitutes. ${ }^{33,34}$ Cells' viability was measured to evaluate the impact of these cryoprotectants.

In this study, we analyzed the impact of freezing and storage on the functionality of skin substitutes and on some of their physicochemical properties in order to evaluate if cryopreservation could be a viable option in the establishment of a skin substitute banking system.

\section{Material and methods}

\section{Patients}

The subjects were Caucasian women aged between 18 and 58 years old. Skin samples used as control $(\circ 23, \circ 26,938,+49$ and 58 ) as well as those used to generate primary human cell banks $(\uparrow 18,+22$ and 938$)$ were derived from breast reduction surgeries. This study was conducted in agreement with the Helsinki declaration and performed under the guidelines of the research ethics committee of the "Centre hospitalier universitaire de Québec." All patients were given adequate information to provide written consent.

\section{Cell culture media}

Fibroblasts were cultured in the high-glucose Dulbecco-Vogt modification of Eagle's medium (DMEM) (Life technologies, Burlington, Canada) supplemented with $10 \%$ fetal calf serum (Hyclone, Logan, USA), 100UI/ml penicillin G (Sigma, Oakville, Canada) and $25 \mu \mathrm{g} / \mathrm{mL}$ gentamicin (Schering Canada, Pointe-Claire, QC, Canada). Keratinocytes were cultured in a combination of highglucose DMEM with Ham's F12 (3:1) supplemented with 5\% Fetal Clone II serum (Hyclone), $5 \mu \mathrm{g} / \mathrm{ml}$ insulin (Sigma, Oakville, Canada), $0.4 \mathrm{ug} / \mathrm{ml}$ hydrocortisone (Calbiochem), $10^{-10} \mathrm{M}$ cholera toxin (Sigma), $10 \mathrm{ng} / \mathrm{ml}$ human epidermal growth factor (Austral Biological, San Ramon, CA), 100UI/ml penicillin G (Sigma) and $25 \mu \mathrm{g} / \mathrm{mL}$ gentamicin (Schering Canada).

\section{Cell culture}

Keratinocytes were extracted using the isolation method with thermolysin and trypsin. ${ }^{35}$ Keratinocytes (passage 1) were seeded at $8 \times 10^{3} \mathrm{cells} / \mathrm{cm}^{2}$ on a feeder layer of irradiated 3T3 mouse fibroblasts. Fibroblasts were extracted using the isolation method with thermolysin and collagenase. ${ }^{36}$ They were seeded at $4 \times 10^{3} \mathrm{cells} / \mathrm{cm}^{2}$ and used at passage 6 for skin substitute's production. All cultures were incubated at $37^{\circ} \mathrm{C}$ in an $8 \% \mathrm{CO}_{2}$ environment and changed three times a week with the media previously described in the cell culture media section. Cells were frozen at $-150^{\circ} \mathrm{C}$ until needed.

\section{Production of skin substitutes}

Skin substitutes were produced according to the self-assembly method. ${ }^{37}$ Briefly, the fibroblasts were cultured in the presence of ascorbic acid at a concentration of $50 \mu \mathrm{g} / \mathrm{ml}$ (Sigma) to form manipulatable sheets. After 28 days, dermal sheets were carefully detached of flasks with curved forceps and superimposed onto one another. After a week, the keratinocytes (passage 2) were seeded on the dermal equivalent to form an epidermal layer. After 7 days of growth, the substitutes were raised at the air-liquid interface and cultured for 21 days. All culture media were changed three times a week.

\section{Freezing of skin substitutes}

At the end of the skin substitute production, some were wrapped in aluminum foil without cryopreservation agent, and frozen directly at $-20^{\circ} \mathrm{C}$ for 2 months. A sample of each fresh human biopsy was frozen in the same manner. Skin substitutes and skin biopsies were directly transferred at $4^{\circ} \mathrm{C}, 24$ hours before analysis.

\section{Percutaneous absorption}

Percutaneous absorption was measured by the standard Franz diffusion cell technique as described by Franz. ${ }^{38}$ Briefly, samples were clamped tightly between the two glass chambers of the diffusion cell (FDC-100 Standard, $0.63 \mathrm{~cm}^{2}$ surface area O-ring; Crown Glass, Somerville, NJ). The receiver compartment was filled with media (DMEM supplemented with penicillin G (Sigma), gentamicin (Schering), and $0.5 \mathrm{mg} / \mathrm{mL}$ of fungizone (Bristol-Myers Squibb Canada, Montréal, Québec, Canada) and maintained at $37^{\circ} \mathrm{C}$ with a water jacket. One hundred microliters of ${ }^{14} \mathrm{C}$ benzoic acid $(0.005 \mathrm{mCi} / 100 \mathrm{uL} /$ chamber) (MP Biomedicals) was deposited on the substitute. Samples were taken at selected intervals $(1,2,4,6,8$, and $24 \mathrm{~h})$ with a $5 \mathrm{~mL}$ syringe prolonged by a catheter $(31 / 2 \mathrm{FR}$ Tom Cat 
Length 41/2) and were conserved at $4^{\circ} \mathrm{C}$ until needed. Radioactivity was determined with a scintillation counter Beckman LS 6000 SC (Beckman Instruments Inc., Fullerton, CA) by adding $0.5 \mathrm{~mL}$ of sample to $4.5 \mathrm{~mL}$ of scintillation fluid Scintisafe ${ }^{\mathrm{TM}} 30 \%$ (Fischer $^{\circ}$ Scientific Ltd., Québec, Québec, Canada).

\section{ATR-FTIR experiments}

Infrared spectra of human skin and substitutes produced with the self-assembly method were obtained using a Golden Gate ${ }^{\mathrm{TM}}$ (Specac Ltd, Londin, UK) single reflection diamond attenuated total reflection. The infrared spectra were recorded with a Nicolet Magna 850 Fourier transform spectrometer (Thermo-Nicolet, Madison, WI) equipped with a narrow band mercury-cadmium-telluride (MCT) detector and a germanium-coated $\mathrm{KBr}$ beam splitter. 128 interferograms were acquired at each temperature, co-added and Fourier transformed using a Happ-Genzel apodization function to give a spectral resolution of $4 \mathrm{~cm}^{-1}$ in the spectral range of 4000 to $750 \mathrm{~cm}^{-1}$. All data were processed with the Grams/AI 8.0 software (Galactic Industries Corporation, Salem, MA). The spectral region, which corresponded to the $\mathrm{CH}_{2}$ stretching band vibrations, was baseline-corrected using a cubic function and the frequency peak position was determined using the center of gravity at the top $10 \%$ of the bands.

\section{Statistical analysis}

Experimental results were expressed as means \pm standard deviation. Cumulative amounts and flux data were analyzed by an analysis of variance (ANOVA) $(p<0.01)$. Infrared data were analyzed using the analysis mixed model with a transformation in log. Results were considered significant when the $p$-value was less than 0.05 . Results were analyzed with the SPSS Statistics program. Effect size for all data was measured using $\mathrm{G}$ power program. According to Cohen's convention a small effect size is $\mathrm{f}^{2}=0.02$ and a large effect size is $\mathrm{f}^{2}=0.35$.

\section{Results}

\section{Kinetics of percutaneous absorption for human skin}

Fluxes of benzoic acid through fresh human skin (Figure 1A) were of linear and almost continuous aspect over 24 hours $(0.15 \pm 0.13 \times 10$ ${ }^{5} \mu \mathrm{g} / \mathrm{cm}^{2} / \mathrm{h}$ at $1 \mathrm{~h}$ and $0.59 \pm 0.40 \times 10^{-5} \mu \mathrm{g} / \mathrm{cm}^{2} / \mathrm{h}$ at $\left.6 \mathrm{~h}\right)$ with a small increase observed at $8 \mathrm{~h}$ and $24 \mathrm{~h}\left(0.89 \pm 0.64 \times 10^{-5} \mu \mathrm{g} / \mathrm{cm}^{2} / \mathrm{h}\right.$ and $1.26 \pm 1.07 \times 10^{-5} \mu \gamma / \mathrm{cm}^{2} / \mathrm{h}$ ). Fluxes obtained with frozen/thawed human skin showed the same tendency, with an increase at $8 \mathrm{~h}\left(0.41 \pm 0.12 \times 10^{-}\right.$ $\left.{ }^{5} \mu \mathrm{g} / \mathrm{cm}^{2} / \mathrm{h}\right)$ and at $24 \mathrm{~h}\left(1.57 \pm 0.95 \times 10^{-5} \mu \mathrm{g} / \mathrm{cm}^{2} / \mathrm{h}\right)$. No significant differences were observed between fluxes of fresh and frozen/thawed human skin.

\section{Kinetics of percutaneous absorption for skin substitutes}

Fluxes of benzoic acid through skin substitutes (Figure 1B) showed a plateau over the first $24 \mathrm{~h}\left(2.06 \pm 1.0 \times 10^{-5} \mu \mathrm{g} / \mathrm{cm}^{2} / \mathrm{h}\right.$ at $1 \mathrm{~h}$ and
$23.01 \pm 23.97 \times 10^{-5} \mu \mathrm{g} / \mathrm{cm}^{2} / \mathrm{h}$ at $24 \mathrm{~h}$ ). Fluxes of frozen/thawed skin substitutes increased over the first hours to reach a steady state between $2 \mathrm{~h}$ and $6 \mathrm{~h}\left(18.93 \pm 7.05 \times 10^{-5} \mu \mathrm{g} / \mathrm{cm}^{2} / \mathrm{h}\right.$ at $2 \mathrm{~h}$ and $22.03 \pm 7.24 \times 10^{-}$ ${ }^{5} \mu \mathrm{g} / \mathrm{cm}^{2} / \mathrm{h}$ at $\left.6 \mathrm{~h}\right)$. Fluxes increased until the end of the experiment $\left(44.27 \pm 1.83 \times 10^{-5} \mu \mathrm{g} / \mathrm{cm}^{2} / \mathrm{h}\right)$. Significant differences were observed at $1,2,4,6,8$ and $24 \mathrm{~h}$ compared with fresh skin substitutes.

\section{Permeability of human skin}

As shown in Table 1, there was no significant main freezing effect on cumulative amount of benzoic acid in human skin $(\mathrm{F}=0.01$, $\mathrm{ddl}=5, \mathrm{p}>0,05$ ). After $1 \mathrm{~h}$, no significant differences were observed in cumulative amount between fresh and frozen/thawed skin biopsies $\left(0.09 \pm 0.08 \times 10^{-5} \mu \mathrm{g}\right.$ and $\left.0.04 \pm 0.02 \times 10^{-5} \mu \mathrm{g}\right)$. Similar results were observed after $2 \mathrm{~h}\left(0.32 \pm 0.28 \times 10^{-5} \mu \mathrm{g}\right.$ and $\left.0.10 \pm 0.03 \times 10^{-5} \mu \mathrm{g}\right)$, $4 \mathrm{~h}\left(0.85 \pm 0.67 \times 10^{-5} \mu \mathrm{g}\right.$ and $\left.0.37 \pm 0.09 \times 10^{-5} \mu \mathrm{g}\right), 6 \mathrm{~h}\left(1.60 \pm 1.16 \times 10^{-5} \mu \mathrm{g}\right.$ and $\left.0.74 \pm 0.18 \times 10^{-5} \mu \mathrm{g}\right), 8 \mathrm{~h}\left(2.72 \pm 1.96 \times 10^{-5} \mu \mathrm{g}\right.$ and $\left.1.25 \pm 0.32 \times 10^{-5} \mu \mathrm{g}\right)$ and $24 \mathrm{~h}\left(15.40 \pm 12.69 \times 10^{-5} \mu \mathrm{g}\right.$ and $\left.17.10 \pm 9.86 \times 10^{-5} \mu \mathrm{g}\right)$ (Figure 2A).

\section{Permeability of skin substitutes}

As shown in table II, there was a significant statistical effect of freezing on cumulative amounts of benzoic acid in skin substitutes $(\mathrm{F}=$ 99.99, ddl $=5, \mathrm{p}<0,001)$. After $1 \mathrm{~h}$, a significant statistical difference was observed in cumulative amount of benzoic acid between fresh and frozen/thawed skin substitutes $\left(1.30 \pm 0.64 \times 10^{-5} \mu \mathrm{g}\right.$ and $5.86 \pm 2.24 \times 10^{-}$ $\left.{ }^{5} \mu \mathrm{g}\right)$. Significant differences were also observed after 2, 4, 6, 8 and $24 \mathrm{~h}$, between cumulative amounts of benzoic acid detected in frozen/ thawed skin substitutes and their fresh counterparts; differences were respectively $6,6,6$, 7and 9 times higher compared with cumulative amounts of benzoic acid detected in fresh skin substitutes (Figure 2B).

ATR-FTIR spectroscopy of fresh and frozen/
thawedhuman skin biopsies $(\circ \mathbf{2 3}, 9 \mathbf{3 8}, 49$ and $\bigcirc \mathbf{5 8})$

The stratum corneumlipid organization of each sample was analyzed by ATR-FTIR spectroscopy (Figure 3A). Frequencies of the symmetric $\mathrm{CH}_{2}$ mode of vibration were measured between $28^{\circ} \mathrm{C}$ and $80^{\circ} \mathrm{C}$. At $28^{\circ} \mathrm{C}$, no significant differences in terms of lipid composition and organization were observed between fresh and frozen/thawed skin biopsy \#23(2849.46 $\pm 0.07 \mathrm{~cm}^{-1}$ and $\left.2849.53 \pm 0.31 \mathrm{~cm}^{-1}\right)$. Similar results were obtained between fresh and frozen/thawed skin biopsy $\# 38\left(2849.97 \pm 0.73 \mathrm{~cm}^{-1}\right.$ and $\left.2849.18 \pm 0.09 \mathrm{~cm}^{-1}\right)$, fresh and frozen/ thawed skin biopsy $\# 49\left(2849.92 \pm 0.07 \mathrm{~cm}^{-1}\right.$ and $\left.2849.63 \pm 0.24 \mathrm{~cm}^{-1}\right)$ and fresh and frozen/thawed skin biopsy \#58 $\left(2849.59 \pm 0.18 \mathrm{~cm}^{-}\right.$ ${ }^{1}$ and $\left.2849.69 \pm 0.42 \mathrm{~cm}^{-1}\right)$. At higher temperatures $\left(80^{\circ} \mathrm{C}\right)$, no significant differences were observed between fresh and frozen/ thawed skin biopsy \#23(2851.95 $\pm 0.42 \mathrm{~cm}^{-1}$ and $\left.2852.51 \pm 0.51 \mathrm{~cm}^{-1}\right)$, neither between fresh and frozen/thawed skin biopsy \#38(2852.01 \pm $0.87 \mathrm{~cm}^{-1}$ and $\left.2852.02 \pm 0.58 \mathrm{~cm}^{-1}\right)$,or between fresh and frozen/ thawed skin biopsy $\# 49\left(2852.11 \pm 0.08 \mathrm{~cm}^{-1}\right.$ and $\left.2852.18 \pm 0.42 \mathrm{~cm}^{-1}\right)$ and fresh and frozen/thawed skin biopsy \#58 $\left(2852.62 \pm 0.32 \mathrm{~cm}^{-1}\right.$ and $\left.2852.10 \pm 0.56 \mathrm{~cm}^{-1}\right)$. Finally, no significant differences were observed in this range of temperatures (Figure $3 \mathrm{~A}$ ). 
Table I Mean fluxes and cumulative amounts of benzoic acid penetration through fresh and frozen/thawed human skin (NHS and FNHS): influence of cryopreservation

\begin{tabular}{|c|c|c|c|c|c|}
\hline & & Fresh (NHS) & & Frozen (FNHS) & \\
\hline Time & Population & $\begin{array}{l}\text { Mean flux }\left(\mathrm{x10}^{-5} \mu \mathrm{g} /\right. \\
\left.\mathrm{cm}^{2} / \mathrm{h}\right)\end{array}$ & $\begin{array}{l}\text { Mean cumulative } \\
\text { amount }\left({\left.\mathrm{x} 10^{-5} \mu \mathrm{g}\right)}\right.\end{array}$ & $\begin{array}{l}\text { Mean flux }\left(\mathrm{x10}^{-5} \mu \mathrm{g} /\right. \\
\left.\mathrm{cm}^{2} / \mathrm{h}\right)\end{array}$ & $\begin{array}{l}\text { Mean cumulative } \\
\text { amount }\left(\times 10^{-5} \mu \mathrm{g}\right)\end{array}$ \\
\hline \multirow{4}{*}{ After $4 \mathrm{~h}$} & 26 & $0,85 \pm 1,05$ & $1,78 \pm 2,20$ & $0,14 \pm 0,08$ & $0,30 \pm 0,20$ \\
\hline & 38 & $0,31 \pm 0,22$ & $0,57 \pm 0,40$ & $0,19 \pm 0,06$ & $0,32 \pm 0,02$ \\
\hline & 49 & $0,10 \pm 0,02$ & $0,21 \pm 0,09$ & $0,28 \pm 0,07$ & $0,49 \pm 0,14$ \\
\hline & Mean & $0,42 \pm 0,32$ & $0,85 \pm 0,67$ & $0,20 \pm 0,06$ & $0,37 \pm 0,09$ \\
\hline \multirow{4}{*}{ After $8 \mathrm{~h}$} & 26 & $1,70 \pm 2,21$ & $5,28 \pm 6,69$ & $0,27 \pm 0,05$ & $0,87 \pm 0,32$ \\
\hline & 38 & $0,83 \pm 0,65$ & $2,36 \pm 1,89$ & $0,40 \pm 0,25$ & $1,23 \pm 0,62$ \\
\hline & 49 & $0,14 \pm 0,02$ & $0,53 \pm 0,11$ & $0,56 \pm 0,02$ & $1,66 \pm 0,11$ \\
\hline & Mean & $0,89 \pm 0,64$ & $2,72 \pm 1,96$ & $0,41 \pm 0,12$ & $1,25 \pm 0,32$ \\
\hline \multirow{4}{*}{ After $24 \mathrm{~h}$} & 26 & $2,76 \pm 3,29$ & $33,10 \pm 39,9$ & $0,50 \pm 0,15$ & $5,91 \pm 1,82$ \\
\hline & 38 & $0,67 \pm 0,60$ & $9,09 \pm 7,95$ & $1,42 \pm 0,12$ & $15,50 \pm 1,84$ \\
\hline & 49 & $0,35 \pm 0,01$ & $4,01 \pm 0,04$ & $2,80 \pm 1,49$ & $29,90 \pm 14,9$ \\
\hline & Mean & $1,26 \pm 1,07$ & $15,40 \pm 12,69$ & $1,57 \pm 0,95$ & $17,10 \pm 9,86$ \\
\hline
\end{tabular}

Table 2 Mean fluxes and cumulative amounts of benzoic acid penetration through fresh and Frozen/thawed skin substitute (SS and FSS): influence of cryopreservation

\begin{tabular}{|c|c|c|c|c|c|}
\hline & & Fresh (SS) & & Frozen (FSS) & \\
\hline Time & Population & $\begin{array}{l}\text { Mean flux }\left(\mathrm{x} 10^{-5} \mu \mathrm{g} /\right. \\
\left.\mathrm{cm}^{2} / \mathrm{h}\right)\end{array}$ & $\begin{array}{l}\text { Mean cumulative } \\
\text { amount }\left(\times 10^{-5} \mu g\right)\end{array}$ & $\begin{array}{l}\text { Mean flux }\left({\mathrm{x} 10^{-5} \mu \mathrm{g} /}\right. \\
\left.\mathrm{cm}^{2} / \mathrm{h}\right)\end{array}$ & $\begin{array}{l}\text { Mean cumulative } \\
\text { amount }\left(\times 10^{-5} \mu \mathrm{g}\right)\end{array}$ \\
\hline \multirow{4}{*}{ After $4 \mathrm{~h}$} & 18 & $6,19 \pm 1,28$ & $13,80 \pm 2,34$ & $27,00 \pm 4,45^{*}$ & $59,10 \pm 5,63 *$ \\
\hline & 22 & $1,32 \pm 0,78$ & $3,31 \pm 1,96$ & $12,90 \pm 3,74 *$ & $26,10 \pm 6,95^{*}$ \\
\hline & 38 & $1,90 \pm 2,00$ & $4,71 \pm 4,90$ & $19,70 \pm 8,35^{*}$ & $43,30 \pm 17,80^{*}$ \\
\hline & Mean & $3,14 \pm 2,17$ & $7.27 \pm 4,65$ & $19,87 \pm 5,76^{*}$ & $42,83 \pm 13.48^{*}$ \\
\hline \multirow{4}{*}{ After $8 \mathrm{~h}$} & 18 & $5,29 \pm 0,93$ & $28,80 \pm 4,91$ & $36,30 \pm 9,44^{*}$ & $139,00 \pm 24,30^{*}$ \\
\hline & 22 & $2,10 \pm 1,64$ & $7,69 \pm 4,95$ & $16,00 \pm 6,90^{*}$ & $62,20 \pm 20,50^{*}$ \\
\hline & 38 & $1,58 \pm 0,47$ & $10,50 \pm 9,87$ & $39,10 \pm 18,80^{*}$ & $127,00 \pm 55,00 *$ \\
\hline & Mean & $2,99 \pm 1,64$ & $15,66 \pm 9,36$ & $30,47 \pm 10,29^{*}$ & $109,40 \pm 33.73 *$ \\
\hline \multirow{4}{*}{ After $24 \mathrm{~h}$} & 18 & $10,80 \pm 3,27$ & $138,00 \pm 37,90$ & $46,70 \pm 6,94 *$ & $610,00 \pm 89,10^{*}$ \\
\hline & 22 & $1,74 \pm 0,97$ & $25,30 \pm 14,80$ & $43,80 \pm 9,11 *$ & $504,00 \pm 92,40 *$ \\
\hline & 38 & $56,50 \pm 65,80$ & $16,20 \pm 16,50$ & $42,30 \pm 3,49^{*}$ & $553,00 \pm 20,90 *$ \\
\hline & Mean & $23,01 \pm 23,97$ & $59,80 \pm 55,40$ & $44,27 \pm 1,83^{*}$ & $555,67 \pm 43,32 *$ \\
\hline
\end{tabular}

All data presented are the mean \pm standard deviation of substitutes replicates of the cell line. The results were confirmed with cells from three patients used to produce the skin substitutes and their frozen counterparts ( $n=3$ substitutes for each cell line). *Significant at $a<0.05$.

Temperature dependence of the frequency of the $\mathrm{CH}_{2}$ symmetric stretching vibration of human skin (NHS) and frozen/thawed human skin (FNHS) obtained following ATR-FTIR spectroscopy analyses. The results were confirmed with biopsies of four different patients and their frozen/thawed counterparts $(n=3$ technical replicates for each biopsy).

\section{ATR-FTIR spectroscopy of fresh and frozen/thawed skin substitutes $(\uparrow 18, \subsetneq 22$ and $q 38)$}

The stratum corneum lipid organization of fresh and frozen/thawed skin substitutes was also analyzed by ATR-FTIR spectroscopy (Figure
3B). Frequencies of the symmetric $\mathrm{CH}_{2}$ mode of vibration were measured between $28^{\circ} \mathrm{C}$ and $80^{\circ} \mathrm{C}$. At $28^{\circ} \mathrm{C}$, no significant differences in lipid organization and composition were observed between fresh and frozen/thawed skin substitutes $\# 18\left(2851.08 \pm 0.33 \mathrm{~cm}^{-1}\right.$ and $2850.79 \pm 0.19 \mathrm{~cm}^{-1}$. Similar results were obtained between fresh and frozen/thawed skin substitutes $\# 22\left(2850.42 \pm 0.09 \mathrm{~cm}^{-1}\right.$ and $\left.2850.79 \pm 0.44 \mathrm{~cm}^{-1}\right)$ and skin substitutes \#38 $\left(2850.70 \pm 0.18 \mathrm{~cm}^{-1}\right.$ and $\left.2850.93 \pm 0.19 \mathrm{~cm}^{-1}\right)$. At higher temperatures $\left(80^{\circ} \mathrm{C}\right)$, no significant differences were observed between fresh and frozen/thawed skin substitutes \#18(2853.54 $\pm 0.40 \mathrm{~cm}^{-1}$ and $\left.2853.79 \pm 0.34 \mathrm{~cm}^{-1}\right)$, fresh and frozen/thawed skin substitutes \#22(2853.05 $\pm 0.17 \mathrm{~cm}^{-1}$ and $\left.2853.29 \pm 0.55 \mathrm{~cm}^{-1}\right)$ and fresh and frozen/thawed skin substitutes 
$\# 38\left(2853.48 \pm 0.56 \mathrm{~cm}^{-1}\right.$ and $\left.2853.75 \pm 0.26 \mathrm{~cm}^{-1}\right)$. No differences were observed in this range of temperatures.

\section{Discussion}

Skin substitutes produced according to the self-assembly method consist of dermal and epidermal layers derived from human fibroblasts and keratinocytes respectively. This method is based on the capacity of fibroblasts to produce their own extracellular matrix. Thus, it allows for the production of skin substitutes exempt of exogenous material. ${ }^{39,40}$ Their epidermal layer is fully differentiated with a welldefined stratum corneum, which shows a good barrier function. ${ }^{41}$ In developing topical drug formulations and assessing their toxic effects, we often need to perform in vitro diffusion experiments through skin. Supplies of human skin are frequently small and erratic, and therefore it may be necessary to store suitable skin until it is required. ${ }^{42}$ Also, necessity of having a fast access to skin substitutes is aimed for both clinical uses (graft) ${ }^{43}$ and applied research (alternative to animals. ${ }^{6}$ As the production of a full thickness skin substitute requires around 63 days of culture, cryoconservation of samples at the end of a batch production has been considered as a good solution in organizing a substitutes banking storage.

The impact of freezing on skin permeability has already been evaluated by other groups showing no differences in the permeability to water and organic solvents..$^{24,25,28}$ It was reported that human skin could usually be stored at $-20^{\circ} \mathrm{C}$ for up to a year with no change in water permeability, but in some cases apparent deterioration of the barrier was observed..$^{44}$ The present study was designed to evaluate the impact of medium-term freezing at $-20^{\circ} \mathrm{C}$ on the functionality and on the physicochemical properties of the stratum corneum barrier of skin substitutes produced according to the self-assembly method.Indeed, the stratumcorneum is the main barrier against skin penetration. It is a continuous sheet of lipids consisting of corneocytes, keratin and a cornified envelope. The assembly is connected by corneodesmosomes and surrounded by extracellular matrix. ${ }^{45}$

We demonstrated that our human skin equivalents mimic many aspects of human skin, namely, the morphology and expression of early and late differentiation markers. ${ }^{41}$ Nevertheless, as reported by other groups, these skin substitutes showed a decreased permeability barrier compared to human skin when performing diffusion studies. ${ }^{46}$ Our results showed that cumulative amounts were not significantly different between fresh and frozen human skin samples where both showed good barrier against benzoic acid (Figure 2A), which is in accordance with the literature. ${ }^{44}$ However, as expected, it was observed that substitutes were more permeable to benzoic acid than human skin for both conditions: fresh and frozen samples (Figure 2B). Indeed, the barrier function of skin substitutes against benzoic acid appeared significantly affected by cryopreservation. Cumulative amounts of benzoic acid were significantly increased for frozen substitutes as soon as $1 \mathrm{~h}$ after the deposition of drug, thus confirming a decrease in the barrier functionality related to the cryopreservation process (Figure 2B). It appears that substitutes were less resistant to cryopreservation than human skin. Fluxes showed the same tendency: significant differences appeared between fresh and frozen skin substitutes only (Figure 1B) and not between fresh and frozen human skin (Figure 1A).

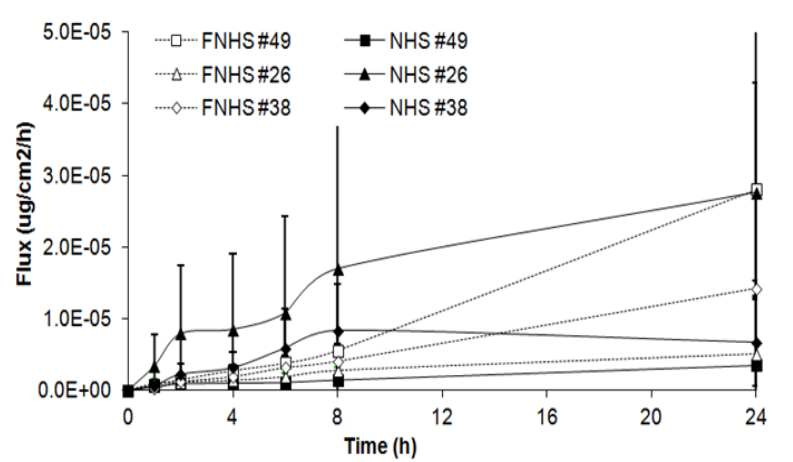

Figure IA Fluxes of benzoic acid through fresh (NHS) and frozen/thawed human skin (FNHS). The samples were taken after I, 2, 4, 6, 8 and 24 hours. The results were confirmed with biopsies of three different patients and their frozen/thawed counterparts ( $n=3$ technical replicates for each biopsy).

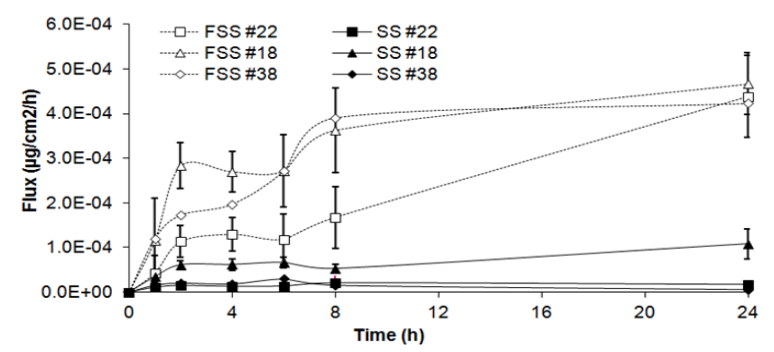

Figure IB Fluxes of benzoic acid through fresh (SS) and frozen/thawed skin substitutes (FSS). The samples were taken after I, 2, 4, 6, 8 and 24 hours. The results were confirmed with cells from 3 different patients used to produce the skin substitutes and their frozen/thawed counterparts $(n=3$ technical replicates for each cell line).

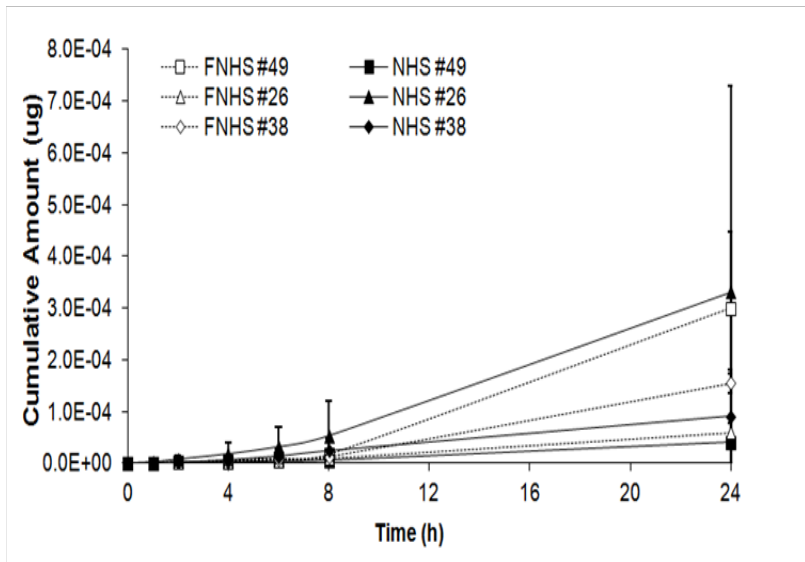

Figure 2A Cumulative amount of benzoic acid through fresh (NHS) and frozen/thawed human skin (FNHS). The samples were taken after I, 2, 4, 6, 8 and 24 hours. The results were confirmed with biopsies of three different patients and their frozen/thawed counterparts $(n=3$ technical replicates for each biopsy). 


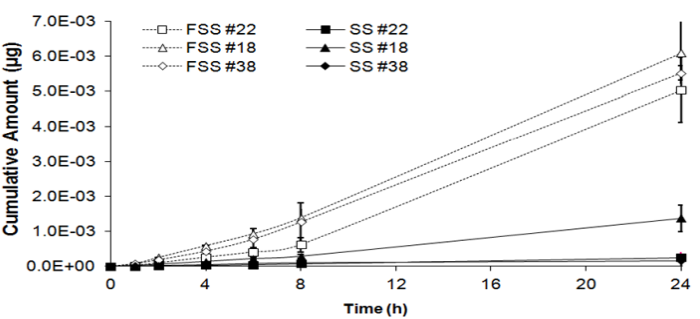

Figure 2B Cumulative amount of benzoic acid through fresh (SS) and frozen/ thawed skin substitutes (FSS). The samples were taken after I, 2, 4, 6, 8 and 24 hours. The results were confirmed with cells from 3 different patients used to produce the skin substitutes and their frozen/thawed counterparts ( $n=3$ technical replicates for each cell line).

One explanation for this decreased barrier function could be related to changes observed in the stratum corneum lipid organization depicted by an increase in the frequencies of the $\mathrm{CH}_{2}$ symmetric stretching vibration (Figure 3B compared with Figure 3A). According to Thakoersing et al. ${ }^{46}$ stratum corneum lipids of skin substitutes adopt a mainly hexagonal packing, whereas human stratum corneum lipids are arranged in a more dense orthorhombic packing. ${ }^{46}$ However, ATR-FTIR results showed a good lipid organization correlation of both conditions: fresh compared with frozen samples whether they are human skin samples (Figure 3A) or skin substitutes (Figure 3B). More precisely, any significant differences were observed between their lipid organization after the freezing process, meaning that it is possible to preserve skin substitutes after cryopreservation up to 2 months without significant variation in their stratum corneum lipid organization (Figure 3B) $(p=0,636)$.

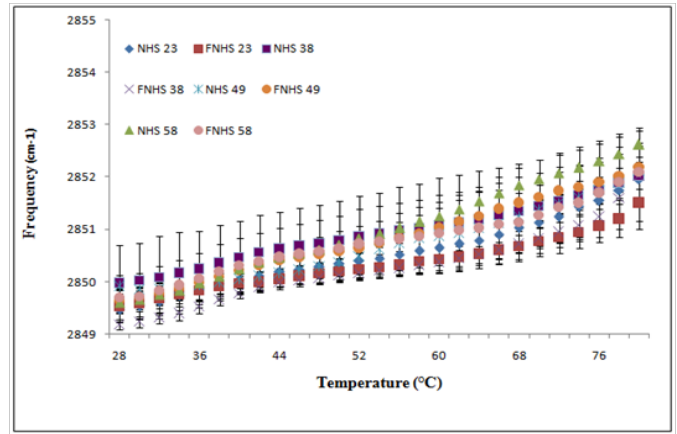

Figure 3A Temperature dependence of the frequency of the $\mathrm{CH} 2$ symmetric stretching vibration of human skin (NHS) and frozen/thawed human skin (FNHS) obtained following ATR-FTIR spectroscopy analyses. The results were confirmed with biopsies of four different patients and their frozen/thawed counterparts ( $n=3$ technical replicates for each biopsy).

Skin models such as Skin Ethics, Epiderm and Episkin appeared to have a more permeable epidermis. Even if all major stratum corneum lipid classes have been found in these skin models, many differences exist such as a decrease in their free fatty acids. ${ }^{47}$ In fact, certain fatty acids are synthetized in the skin; others are necessarily obtained from the diet. ${ }^{45}$ The major classes of lipids found in the stratum corneum are ceramides, free fatty acids and cholesterol $1.48,49$ Consequently, differences in the composition of the stratum corneum could be another explanation for the affected functionality of the skin and therefore its capacity of physical shock adaptation such as cryopreservation.

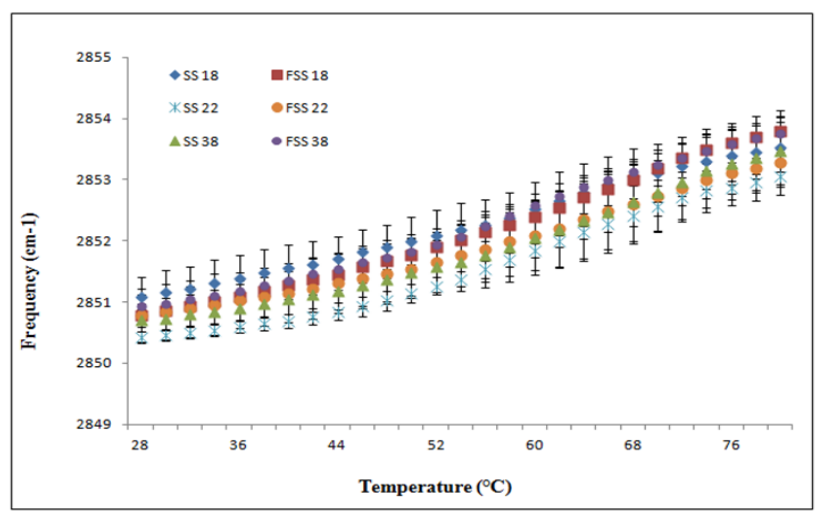

Figure 3B Temperature dependence of the frequency of the $\mathrm{CH} 2$ symmetric stretching vibration of skin substitute (SS) and frozen/thawed skin substitutes (FSS) produced according to the self-assembly method obtained following ATR-FTIR spectroscopy analyses. The results were confirmed with cells from three different patients used to produce the skin substitutes and their frozen/ thawed counterparts ( $n=3$ technical replicates for each cell line).

Moreover, it is known that cryopreservation causes ice crystal formation ${ }^{50,51}$ which, we believe, could perturb the integrity of skin substitutes. It was suggested that a slow cooling of substitutes until lower cryopreservation temperatures could reduce the size of ice crystals and therefore their impact. Nevertheless, cryopreservation at lower temperatures requires the use of cryopreservation agents such as DMSO and glycerol to help the conservation of cells' integrity. As our studies are considered in a perspective of pharmaceutical testing, use of these cryopreservation agents should be avoided because they are known to increase skin permeability. ${ }^{52,53}$

These results indicate that ice crystals are probably formed on the keratins, which are known as hygroscopic molecules, while the freezing process occurs in the skin substitutes. ${ }^{54}$ These observations suggest that keratin and lipids have an important role in maintaining the barrier function of the stratum corneum. $t$ is clear that human skin samples are less affected by cryopreservation compared with skin substitutes produced according to the self-assembly method. Even though our skin substitutes are able to reproduce many physicochemical properties of human skin, an investigation of their lipid composition is essential to improve their barrier function.

Finally, these results demonstrate that cryopreservation neither affects the functionality nor the lipid composition of human skin. However, a significant increase in skin substitutes' permeability to benzoic acid was observed, thus suggesting that functionality of the stratum corneum barrier was affected by the freezing process, despite ATR-FITR results showing that its structural integrity was preserved compared to its fresh counterpart. The results of these experiments reaffirm the critical role that lipids play in the barrier function. Thus, abnormalities in the lipid composition and metabolism of skin substitutes are still of topical interest. As previously reported, it is 
recommended that skin freezing not be used in absorption studies where skin viability and metabolism might be contributing factors to the study. ${ }^{55}$ Finally, the protein-lipid interactions are critical for the maintenance of the barrier function, and more precisely, a lack of the hydroxy-ceramide lipid envelope, which is formed on the outside of the protein envelope, could be one of the failures in forming a good skin barrier. While we know that our fresh skin substitutes showed functionality results not that far from their in vivo counterpart, it appeared that there are still noticeable differences with their frozen counterparts, which are probably related to some important lipids such as specific ceramides. A focus of future research will be to work on the modulation of stratum corneum lipid composition of these skin substitutes and to determine their metabolic capabilities.

\section{Acknowledgements}

None.

\section{Conflict of interest}

The author declares no conflict of interest.

\section{References}

1. Maziere JC. Histo-Physiologie de la peau et lipides cutanés-Structure de l'épiderme et particularités du métabolisme des lipides en relation avec la fonction barrière hydrique de la peau. Oléagineux, Corps gras, Lipides. 1997;4:258-265.

2. Dougherty WR, Chalabian JR. Skin substitutes. West J Med. 1995;162(6):540-541.

3. Auxenfans C, Fradette J, Lequeux C, et al. Evolution of three dimensional skin equivalent models reconstructed in vitro by tissue engineering. Eur $J$ Dermatol. 2009;19(2):107-113.

4. Fentem J, Chamberlain M, sangster B. The feasibility of replacing animal testing for assessing consumer safety: A suggested future direction. Altern Lab Anim. 2004;32(6):617-623.

5. Welss T, Basketter DA, Schroder KR. In vitro skin irritation: facts and future. State of the art review of mechanisms and models. Toxicol In Vitro. 2004;18(3):231-243.

6. Chen F, Zhang W, Wu W, et al. Cryopreservation of tissue-engineered epithelial sheets in trehalose. Biomaterials. 2011;32(33):8426-8435.

7. Jean J. Application dermopharmaceutiques: développement d'un modèle de substituts cutanés psoriasiques par génie tissulaire. Faculté de pharmacie, Québec : Université Laval; 2010.

8. Melissopoulos IA, Levacher C. La peau: structure et physiologie. Paris, France: 1998.

9. Schaefer H, Redelmeier TE. Skin barrier: principles of percutaneous absorption. S. Karger; 1996. 310 p.

10. Kenneth AW. Dermatological and Transdermal Formulation. USA : CRC Press; 2002. $592 \mathrm{p}$.

11. Bernard G, Auger M, Soucy J, et al. Physical characterization of the stratum corneum of an in vitro psoriatic skin model by ATR-FTIR and Raman spectroscopies. Biochim Biophys Acta. 2007;1770(9):1317-1323.

12. Golden GM, Guzek DB, Harris RR, et al. Lipid thermotropic transitions in human stratum corneum. J Invest Dermatol. 1986;86(3):255-259.

13. Hawkin GS, Reifenrath WG. Development of an in vitro model for determining the rate of chemicals applied to skin. Fundam Appl Toxicol. 1984;4(2 Pt 2):133-144.14.
14. Bosman IJ, Ensing K, De Zeeuw RA. Standardization procedure for the in vitro skin permeation of anticholinergics. International Journal of Pharmaceutics.1998;169(1):65-73.

15. Barbero AM, Frasch HF. Pig and guinea pig skin as surrogates for human in vitro penetration studies: a quantitative review. Toxicol In Vitro. 2009;23(1):1-13.

16. Hadzija BW, Ruddy SB, Ballenger ES. Effect of freezing on iontophoretic transport through hairless rat skin. J Pharm Pharmacol. 1992;44(5):387390

17. Babu RJ, Kanikkannan N, Kikwai L, et al. The influence of various methods of cold storage of skin on the permeation of melatonin and nimesulide. J Control Release. 2003;86(1):49-57.

18. Schmook FP, Meingassner JG, Billich A. Comparison of human skin or epidermis models with human and animal skin in in-vitro percutaneous absorption. Int J Pharm. 2001;215(1-2):51-56.

19. Holland JM, Kao JY, Whitaker MJ. A multisample apparatus for kinetic evaluation of skin penetration in vitro: the influence of viability and metabolic status of the skin. Toxicol Appl Pharmacol. 1984;72(2):272280.

20. Yazdanian M. The effect of freezing on cattle skin permeability. International Journal of Pharmaceutics. 1994;103(1):93-96.

21. Kemppainen BW, Riley RT, Pace JG, et al. Effects of skin storage conditions and concentration of applied dose on [3H]T-2 toxin penetration through excised human and monkey skin. Food Chem Toxicol. 1986;24(3):221-227.

22. Ahlstrom LA, Cross SE, Mills PC. The effects of freezing skin on transdermal drug penetration kinetics. $J$ Vet Pharmacol Ther 2007;30(5):456-463.

23. Schreiber S, Mahmoud A, Vuia A, et al Reconstructed epidermis versus human and animal skin in skin absorption studies. Toxicol In vitro. 2005;19(6):813-822.

24. Burch GE, Winsor T. Rate of insensible perspiration (diffusion of water) locally through living and through, dead human skin. Arch Intern Med. 1994:174(6):437-444.

25. Bronaugh RL, Stewart RF, Simon M. Methods for in vitro percutaneous absorption studies. VII: Use of excised human skin. J Pharm Sci. 1986;75(11):1094-1097.

26. Swarbrick J, Lee G, Brom J. Drug permeation through human skin: I. Effect of storage conditions of skin. J Invest Dermatol. 1982;78(1):63-66.

27. Moody RP, Martineau PA. An automated in vitro dermal absorption procedure: I. Permeation of (14) C-labelled N,N-diethyl-m-toluamide through human skin and effects of short-wave ultraviolet radiation on permeation. Toxicol In Vitro. 1990;4(3):193-199.

28. Nakai JS, Chu I, Li-Muller A, et al. Effect of environmental conditions on the penetration of benzene through human skin. J Toxicol Environ Health. 1997;51(5):447-462.

29. Nakai JS, Stathopulos PB, Campbell GL, et al. Penetration of chloroform, trichloroethylene, and tetrachloroethylene through human skin. $J$ Toxicol Environ Health A. 1999;58(3):157-170.

30. Astley JP, Levine M. Effect of dimethyl sulfoxide on permeability of human skin in vitro. J Pharm Sci. 1976;65(2):210-215.

31. Harriger MD, Supp AP, Swope VB, et al. Reduced engraftment and wound closure of cryopreserved cultured skin substitutes grafted to athymic mice. Cryobiology. 1997;35(2):132-142.

32. Teepe RG, Koebrugge EJ, Ponec M, et al. Fresh versus cryopreserved 
cultured allografts for the treatment of chronic skin ulcers. $\mathrm{Br} J$ Dermatol. 1990;122(1):81-89.

33. Wang X, Hua TC, Sun DW, et al. Cryopreservation of tissue-engineered dermal replacement in Me2SO: Toxicity study and effects of concentration and cooling rates on cell viability. Cryobiology. 2007;55(1):60-65.

34. Kuroyanagi $\mathrm{Y}$, Kubo K, Matsui H, et al. Establishment of banking system for allogeneic cultured dermal substitute. Artif Organs. 2004;28(1):13-21.

35. Germain L, Rouabhia $M$, Guignard $R$, et al. Improvement of human keratinocyte isolation and culture using thermolysin. Burns. 1993;19(2):99-104.

36. Auger FA, Lopez Valle CA, Guignard R, et al. Skin equivalent produced with human collagen. In Vitro Cell Dev Biol Anim. 1995;31(6):432-439.

37. Jean J, Lapointe M, Soucy J, et al. Development of an in vitro psoriatic skin model by tissue engineering. J Dermatol Sci. 2009;53(1):19-25.

38. Franz TJ. Percutaneous absorption on the relevance of in vitro data. $J$ Invest Dermatol. 1975;64(3):190-195.

39. Auger FA, Rémy-Zolghadry M, Grenier G, et al. The self-assembly approach for organ reconstruction by tissue engineering. The Journal of Regenerative Medicine. 2000;1(5):75-86.

40. Auger F, Remy-Zolghadri M, Grenier G, et al. A truly new approach for tissue engineering: the LOEX self-assembly technique. In Stem cell transplantation and tissue engineering. Ernst Schering Res Found Workshop. 2002;35:73-88

41. Jean J, Bernard G, Duque-Fernandez A, et al. Effects of serum-free culture at the air-liquid interface in a human tissue-engineered skin substitute. Tissue Eng Part A. 2011;17(7-8):877-888.

42. Harrison S, Barry B, Dugard P. Effects of freezing on human skin permeability. J Pharm Pharmacol. 1984;36(4):261-262.

43. Kubo K, Kuroyanagi Y. The possibility of long-term cryopreservation of cultured dermal substitute. Artif Organs. 2005;29(10):800-805.

44. Bronaugh RL, Stewart RF, Simon M. Methods for in vitro percutaneous absorption studies VII: use of excised human skin. J Pharm Sci. 1986;75(11):1094-1097.
45. Proksch E, Brandner JM, Jensen JM. The skin: an indispensable barrier Exp Dermatol. 2008;17(12):1063-1072.

46. Thakoersing VS, Smeden J, Boiten WA, et al. Modulation of stratum corneum lipid composition and organization of human skin equivalents by specific medium supplements. Experimental dermatology. 2015;24(9):669-674.

47. Ponec M, Weerheim A, Kempenaar J, et al. The formation of competent barrier lipids in reconstructed human epidermis requires the presence of vitamin C. J Invest Dermatol. 1997;109(3):348-355.

48. Downing DT, Stewart ME, Wertz PW, et al. Skin lipids an update. J Invest Dermatol. 1987;88(3 suppl):2s-6.

49. van Smeden J, Boiten WA, Hankemeier T, et al. Combined LC/MSplatform for analysis of all major stratum corneum lipids, and the profiling of skin substitutes. Biochim Biophys Acta. 2014;1841(1):70-79.

50. Mazur P. Kinetics of water loss from cells at subzero temperatures and the likelihood of intracellular freezing. J Gen Physiol. 1963;47:347-369.

51. Pegg DE. The relevance of ice crystal formation for the cryopreservation of tissues and organs. Cryobiology. 2010;60(3 Suppl):S36-44.

52. Bjorklund S, Engblom J, Thuresson K, et al. Glycerol an urea can be used to increase skin permeability in reduced hydratation conditions. European Journal of Pharmaceutical sciences. 2013;50(5):638-645.

53. Chandrasekaran SK, Campbell PS, Michaels AS. Effect of dimethylsulfoxide on drug permeation through human-skin. Aiche Journal. 1977;23(6):810-816.

54. Wrześniewska-Tosik K, Wawro D, Stęplewski W, et al. Fibrous products with keratin content". Fibres \& Textiles in Eastern Europe. 2007;15:61.

55. Wester RC, Christoffel J, Hartway T, et al. Human cadaver skin viability for in vitro percutaneous absorption: storage and detrimental effects of heat-separation and freezing. Pharm Res. 1998;15(1):82-84. 